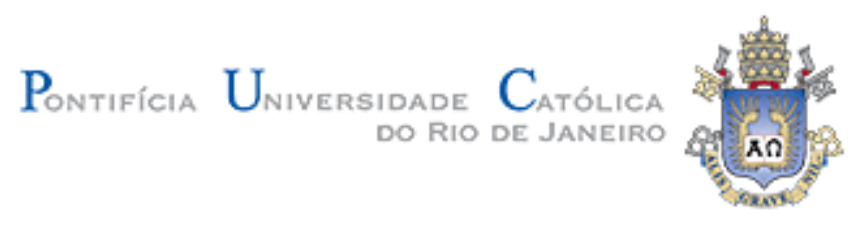

Rogério Soares da Costa

\title{
A Epistemologia Pós-Darwiniana de Sir Karl Popper
}

Dissertação apresentada ao Programa de Pós-graduação em Filosofia da PUC-Rio como requisito parcial para obtenção do título de Mestre em Filosofia.

Orientador: Professor Carlos Alberto Gomes dos Santos

Rio de Janeiro Março de 2007 


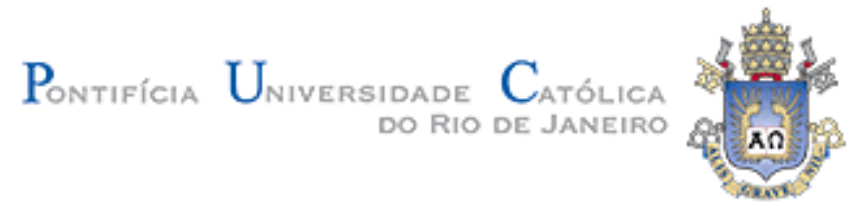

Rogério Soares da Costa

\title{
“ A Epistemologia Pós-Darwiniana de Sir Karl Popper “
}

\begin{abstract}
Dissertação apresentada ao Programa de Pós-graduação em Filosofia da PUC-Rio como requisito parcial para obtenção do grau de Mestre em Filosofia. Aprovada pela Comissão Examinadora abaixo assinada.
\end{abstract}

Prof. Carlos Alberto Gomes dos Santos

Orientador

Departamento de Filosofia - PUC-Rio

Prof. Sérgio Luiz de Castilho Fernandes

Departamento de Filosofia - PUC-Rio

Prof. Antonio Augusto Passos Videira UERJ

Prof. Paulo Fernando Carneiro de Andrade

Coordenador Setorial do Centro de Teologia e Ciências Humanas - PUC-Rio 
Todos os direitos reservados. É proibida a reprodução total ou parcial do trabalho sem autorização da universidade, do autor e do orientador.

\section{Rogério Soares da Costa}

Graduou-se em Filosofia pela Universidade do Estado do Rio de Janeiro em 2005. Pesquisa na área da Epistemologia e da Teoria do Conhecimento, centrando-se num questionamento acerca do estatuto epistemológico do método científico e do raciocínio causal-indutivo.

Ficha Catalográfica

Costa, Rogério Soares da

A epistemologia pós-darwiniana de Sir Karl Popper / Rogério Soares da Costa ; orientador: Carlos Alberto Santos. -2007.

74 f. : il. ; $30 \mathrm{~cm}$

Dissertação (Mestrado em Filosofia)-Pontifícia Universidade Católica do Rio de Janeiro, Rio de Janeiro, 2007.

Inclui bibliografia

1. Filosofia - Teses. 2. Epistemologia. 3. Epistemologia evolucionária. 4. Filosofia. 5. Darwinismo. 6. Neodarwinismo. 7. Indução. 8. Conjecturas e refutações. I. Santos, Carlos Alberto. II. Pontifícia Universidade Católica do Rio de Janeiro. Departamento de Filosofia. III. Título. 


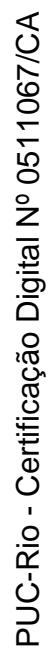

Para minha mãe Maria Regina e para meu irmão Daniel. 


\section{Agradecimentos}

Agradeço primeiramente a meu orientador Professor Doutor Carlos Alberto Gomes dos Santos pela confiança, apoio e dedicação durante a realização desta pesquisa.

Ao Professor Doutor Antonio Augusto Passos Videira, pela gentileza e atenção em atender a meu convite para fazer parte desta banca de avaliação.

Ao Professor Doutor Sérgio Fernandes Castilho, que desde o início de meu curso na pósgraduação causou-me profunda impressão por sua extensa cultura filosófica e seu corajoso posicionamento frente às mais desconcertantes questões da existência humana.

Especial gratidão dedico ao Professor Doutor Luiz Eduardo de Oliveira Bicca, da Universidade do Estado do Rio de Janeiro, pelo apoio e incentivo para o meu ingresso no programa de pós-graduação da PUC-RIO.

Agradeço aos meus irmãos Jorge Bezerra e Igor Nobre de Melo pelo amor, ternura e afeição testemunhados na nossa preciosa amizade de mais de uma década.

Ao meu amigo Ulisses Marques Carratti, companheiro fiel e inestimável, um oásis de sinceridade e acolhimento, por seu carinho e atenção nesses já seis anos de amizade.

Ao meus amigos Tiago Barros e Rommel Luz que aturam pacientemente minhas crises existenciais.

Afeição especial dedico aos meus amigos da cena underground, em particular ao nobre Cícero, irmão e amigo do peito, que demonstram com suas atitudes o verdadeiro espírito underground de independência no gosto musical e resistência à massificação.

À Cecilia Voronoff, a quem tudo o que posso dizer, sem violar a beleza do inexprimível que nos une, é repetir a eterna fórmula do desejo: eu te amo.

Agradeço aos colegas da PUC-RIO, Raquel Anna Sapuraru e Fábio Creder pela torcida por minha aprovação para o doutorado e a todos que fizeram, de alguma forma, parte dessa etapa de minha vida.

Ao CNPQ, sem cujo apoio essa dissertação não seria possível. 


\section{Resumo}

Soares da Costa, Rogério; Gomes dos Santos, Carlos Alberto. A Epistemologia Pós-Darwiniana de Sir Karl Popper. Rio de Janeiro, 2007. 74p. Dissertação de Mestrado - Departamento de Filosofia, Pontifícia Universidade Católica do Rio de Janeiro.

A Epistemologia Pós-Darwiniana de Sir Karl Popper é uma tentativa de esclarecer um ponto específico da obra do filósofo austríaco Karl Popper: a função da teoria evolutiva de Charles Darwin na obra epistemológica tardia. Alguns críticos encontram na epistemologia evolucionária, núcleo da obra tardia de Popper, uma virada naturalista baseada na biologia. O principal objetivo dessa dissertação é negar tais interpretações. As bases de aproximação de Popper com o darwinismo em sua epistemologias são lógicas e não naturalísticas. De acordo com Popper, a estrutura lógica do darwinismo ( seus elementos a priori ) é a mesma do processo de conjecturas e refutações do raciocínio dedutivo. Isso explica porquê o darwinismo, que não é uma teoria científica, mas um programa metafísico de pesquisa, pode ser tão frutífero e útil para a ciência. Assim, se estivermos certos, o rótulo de naturalismo aplicado à obra epistemológica tardia de Karl Popper é um simples caso de má interpretação.

\section{Palavras - chave}

Epistemologia; epistemologia evolucionária; filosofia; darwinismo; neodarwinismo; indução; conjecturas e refutações; lógica; ciência; naturalismo. 


\section{Abstract}

Soares da Costa, Rogério; Gomes dos Santos, Carlos Alberto (Advisor). The Sir Karl Popper`s PostDarwinian Epistemology. Rio de Janeiro, 2007. 74p. MSc. Dissertation - Departamento de Filosofia, Pontifícia Universidade Católica do Rio de Janeiro.

The Sir Karl Popper's PostDarwinian Epistemology intends to clarify an specific issue: the function of Evolutionary Theory by Charles Darwin in Sir Karl Popper`s late epistemological works. Some critics find a naturalistic turn based on biological grounds in the evolutionary epistemology, bulk of the late works of Popper. The main objective of this dissertation is to deny these interpretations. The basis of Popper`s approach to Darwinism in his epistemology is not naturalistic but logical. According to Popper, the logical structure (a priori elements) of Darwinism is the same of conjecture and refutation process of deductive reasoning. This explains why Darwinism, which is not a scientific theory but a metaphysical research program, is so fruitful and helpful to science. Hence, if we are right, the label of naturalism attributed to the late epistemological works of Karl Popper is a simple case of misunderstanding.

\section{Keywords}

Epistemology; evolutionary epistemology; philosophy; Darwinism; Neodarwinism; induction; conjectures and refutations; logic; science; naturalism. 


\section{Sumário}

1.Introdução

2. Caracterização do pensamento epistemológico de Sir Karl Popper

2.1. Indução e demarcação

2.2. O método dedutivo de testes 22

2.3. Teorias, observação e objetividade científica 24

2.4. A teoria dos três mundos 30

2.5. A linguagem 34

3. A epistemologia pós-darwiniana de Sir Karl Popper 38

3.1. A teoria evolutiva de Charles Darwin 38

3.2. Charles Darwin e a epistemologia de Sir Karl Popper 45

3.3. Darwinismo, cientificidade e lógica 56

4. Conclusão 66

5. Referências bibliográficas $\quad 69$ 
As soluções experimentais que animais e plantas incorporam em sua anatomia e em seu comportamento são análogos biológicos de teorias; e vice-versa: as teorias correspondem ( tal como muitos produtos exossomáticos como favos de mel, e especialmente instrumentos endossomáticos como teias de aranha) a órgãos endossomáticos e seus modos de funcionamento. Assim como as teoria, os órgãos e suas funções são adaptações experimentais ao mundo em que vivemos.

Sir Karl Popper ( 1994a, p.143) 